\title{
Maintenance Intravenous Fluids in Children - The Verdict was Already Out?
}

\author{
Javed Ismail ${ }^{1}$. Jhuma Sankar ${ }^{2}$ (D) \\ Received: 26 July 2019 / Accepted: 26 July 2019 / Published online: 22 August 2019 \\ (C) Dr. K C Chaudhuri Foundation 2019
}

Maintenance intravenous fluid (IVF) is a common and essential part of treatment in hospitalized children to maintain hydration in those in whom enteral fluid intake is not possible. An ideal IVF should match the daily fluid volume requirements and should contain electrolytes in appropriate concentrations to replenish ongoing loss and daily needs. There has been an ongoing debate on the tonicity of IVF for maintenance requirements over the past few decades. Tonicity or osmotic pressure exerted by the IVF on the semipermeable cell wall membrane is determined by the electrolyte concentration; the major contributor being sodium. Hypotonic maintenance IVF has been traditionally used in children based on theoretical calculations by Holliday and Segar in 1950s which yielded a fluid composition of $3 \mathrm{mEq} / \mathrm{dL}$ of sodium and $2 \mathrm{mEq} / \mathrm{dL}$ of potassium [1]. In acutely ill states, excess secretion of arginine vasopressin retains free water and can exacerbate hyponatremia associated with administration of hypotonic fluids. This results in a range of mild to severe hyponatremia, in extreme cases manifesting as hyponatremic encephalopathy. Isotonic fluids have been recommended since 2003 as a maintenance IVF in hospitalized children to prevent these complications [2]. In recent years, there has been a fear of inducing complications like hypernatremia, volume overload, edema and hypertension with use of isotonic saline.

In this issue of journal, Bagri et al. compared isotonic normal saline $(0.9 \%$ sodium chloride with $5 \%$ dextrose) $v s$. hypotonic half normal saline $(0.45 \%$ sodium chloride with $5 \%$

Jhuma Sankar

jhumaji@gmail.com

1 Department of Pediatrics, Apollo Hospital, Vellore, Tamil Nadu, India

2 Department of Pediatrics, All India Institute of Medical Sciences, New Delhi 110029, India dextrose) as maintenance fluid of choice in a single centre randomized controlled trial [3]. The primary outcome was incidence of hyponatremia $(<130 \mathrm{mEq} / \mathrm{L})$ at $24 \mathrm{~h}$ which was comparable between the groups. Similarly, the incidence of hypo or hypernatremia was comparable at 24 and $48 \mathrm{~h}$ of admission. However, the serum sodium was significantly higher in the normal saline group compared to $N / 2$ saline $(138.3 \pm 6 \mathrm{mEq} / \mathrm{L}$ vs. $135.1 \pm 4.4 \mathrm{mEq} / \mathrm{L} ; p$ value $<0.01)$. Based on the results of this study, it would be imprudent to conclude that $\mathrm{N} / 2$ saline does not cause hyponatremia as the observed rate of hyponatremia is $6.7-8 \%$ whereas, the rate presumed for sample size calculation was $35 \%$, almost 5 times that of actual incidence. The study is therefore underpowered to make any recommendations based on the findings.

Evidence based recommendations based on many randomized trials and systematic reviews continue to recommend isotonic IVF as maintenance fluid of choice $[4,5]$. There are real concerns with use of isotonic $0.9 \%$ normal saline like, hyperchloremic metabolic acidosis, systemic inflammation and renal tubular injury which have been addressed in recent trials. Balanced crystalloids like Plasmalyte or Ringer's Lactate fare better in these aspects compared to normal saline and warrant further investigation as maintenance fluids in hospitalized children.

\section{Compliance with Ethical Standards}

Conflict of Interest None.

\section{References}

1. Holliday MA, Segar WE. The maintenance need for water in parenteral fluid therapy. Pediatrics. 1957;19:823-32.

2. Moritz ML, Ayus JC. Prevention of hospital-acquired hyponatremia: a case for using isotonic saline. Pediatrics. 2003;111:227-30. 
3. Bagri NK, Saurabh VK, Basu S, Kumar A. Isotonic versus hypotonic intravenous maintenance fluids in children: a randomized controlled trial. Indian J Pediatr. 2019. https://doi.org/10.1007/s12098-01903011-5.

4. Feld LG, Neuspiel DR, Foster BA, et al. Clinical practice guideline: maintenance intravenous fluids in children. Pediatrics. 2018;142: e20183083.
5. National Clinical Guideline Centre. IV Fluids in children: intravenous fluid therapy in children and young people in hospital [Internet]. London: National Institute for Health and Care Excellence (UK); 2015. Available at: http://www.ncbi.nlm.nih.gov/ books/NBK338141/. Accessed 23rd July 2019.

Publisher's Note Springer Nature remains neutral with regard to jurisdictional claims in published maps and institutional affiliations. 